\title{
Multi-Criteria Evaluation of End-of-Life Vehicles' Dismantling Scenarios with Respect to Technical Performance and Sustainability Issues
}

\author{
Alexis Schmid ${ }^{1}$, Mireille Batton-Hubert ${ }^{2}$, Pascale Naquin ${ }^{3}$ and Rémy Gourdon ${ }^{4, *}$ \\ 1 Société GAIA Conseils, Quincieux 69650, France; a.schmid@gaia-conseils.fr \\ 2 Mines Saint-Etienne, LIMOS UMR CNRS 6158, 158 Cours Fauriel, Saint-Etienne 42023, France; \\ mireille.batton-hubert@emse.fr \\ 3 INSAVALOR, Division PROVADEMSE, Villeurbanne Cedex 69603, France; pascale.naquin@cefrepade.org \\ 4 Univ Lyon, INSA Lyon, DEEP, 20 Avenue A. Einstein, Villeurbanne CEDEX 69621, France \\ * Correspondence: Remy.Gourdon@insa-lyon.fr; Tel.: +33-047-243-8170
}

Academic Editor: Xianlai Zeng

Received: 9 September 2016; Accepted: 28 November 2016; Published: 6 December 2016

\begin{abstract}
Three scenarios of dismantling and shredding operations of end-of-life vehicles (ELVs) were compared in this study with respect to technical and sustainability criteria, according to the level of dismantling applied to the vehicles. The scenarios differed from each other in the extent of the dismantling operations. They were implemented experimentally at the industrial scale on representative samples of 120 vehicles. The data collected from the monitoring of the experimental campaigns were used as feed data for the multi-criteria analysis of the scenarios using the PROMETHEE method. Nine criteria of evaluation were selected, namely global warming, local environmental impacts, tropospheric ozone production, ecotoxicity, operational costs, investment costs, occupational risks, employability, and technical performance. The medium-level dismantling scenario was identified as the best scenario with respect to the criteria of evaluation. This scenario included the steps of depollution, followed by the removal of easily accessible and identifiable plastics and glasses. Reasonable changes in the ponderation of the evaluation criteria did not significantly affect the ranking.
\end{abstract}

Keywords: end-of-life vehicles (ELVs); dismantling; shredding; reuse; recovery; recycling; multi-criteria analysis; sustainability

\section{Introduction}

Regulatory requirements and recovery targets for the management of end-of-life vehicles (ELVs) have been increased significantly in the last 15 years under the impulsion of the European Community (EC). However, the latest available report in France (Lecointre and Filmon, [1]), relative to year 2013, indicates an actual percentage of material recovery (reuse and recycling) of $85.3 \%$ of ELVs' mass $(82.6 \%$ and $85.7 \%$ in years 2012 and 2014, respectively, personal communication), and a percentage of material and energy recovery of $89.3 \%$ ( $87.1 \%$ in 2012 and $91.1 \%$ 2014, personal communication). Even though the levels of performance are continuously growing, they remain below the target of $95 \%$ (including $10 \%$ energy recovery) set for January 2015 by European directive 2000/53/CE [2].

A regulatory framework has been defined by the order of 2 May 2012, where recovery targets have been set for deconstruction, shredding and post-shredding operations respectively. However, economic, environmental and social issues have not actually been integrated in the current European regulatory and legislative approaches. For example, the hierarchy of waste management operations defined by the Framework Directive prioritizes reuse and material recovery versus energy recovery, 
without integrating economic, environmental and social issues that may possibly modify the hierarchy in some situations. Regulations on Extended Producer Responsibility (EPR) have given the same preference to technical performance when setting targets for ELVs as for other end-of-life products such as electrical and electronic equipment, demolition waste and, more recently, furniture. Yet, if a minimal level of technical performance is obviously required for any industrial system to be viable (including waste management and recycling), other criteria relative to environmental and social issues also need to be considered according to the sustainable development principles. Hence for the ELV sector, targets on the percentage of material and energy recovery should be associated to social, environmental, and economic considerations to achieve the best compromise in terms of sustainable development in all issues.

Fonseca et al. [3] compared, on a theoretical basis, different scenarios for the management of ELVs using a life cycle assessment methodology in which five impact categories were considered. The best scenario identified included additional dismantling of some components for material and energy recovery. The authors of the paper reported that the best scenario would not only allow to comply with the EC targets but also provide environmental benefits. Ahmed et al. [4] proposed an integrated model to evaluate sustainable alternatives in the management of ELVs using a multi-criteria analysis method. They proposed to construct an analytic hierarchy process (AHP) using a fuzzy approach to identify the most suitable alternative with respect to sustainable development principles.

In previous articles, Schmid [5] and Schmid et al. [6,7] compared the French and German approaches, which encouraged, respectively, a high dismantling level prior to shredding or an optimized development of sorting technologies after shredding. Three scenarios were implemented experimentally on an industrial ELV dismantling and shredding plant. The scenarios differed from each other by the level of dismantling of the ELVs and were firstly compared with regards to their technical performance. In addition to the measurements done to calculate the percentages of material and energy recovery, many data were recorded in this experimental program regarding environmental emissions at different stages of the treatment line including depollution, dismantling and shredding/sorting operations. The objective of the present article was to exploit the database thus constituted in order to compare the three scenarios not only according to their technical performance but also more globally with respect to sustainability issues, using an appropriate multi-criteria analysis.

Multi-criteria analysis allows to integrate objective data (such as technical performance) and more subjective criteria to compare different alternative actions as an aid to decision making. Various methods have been proposed, among which the PROMETHEE method (Preference Ranking Organization METHod for the Enrichment of Evaluations) appears as the most widely used. Its principle is to consider that one given action would outclass an alternative action if it is least as good as the alternative with respect to a majority of the criteria of evaluation, and not worse than the alternative on any of the other criteria. The method mathematically defines threshold values to decide whether the assumption may be validated. Ponderation factors may also be considered to express possible priorities given to some of the criteria.

A similar study was conducted in Cyprus in 2007 (Mergias et al. [8] to compare six scenarios with respect to 17 qualitative and quantitative criteria using PROMETHEE II method. The best two scenarios identified in this study were (i) partial dismantling followed by energy recovery from the combustible fraction of shredding residues and incorporation of the non-combustible fraction into cement production; and (ii) partial dismantling followed by landfill disposal of shredding residues. However, this study was based on literature data and referred to a socio-economic background quite different from that of Western Europe. Li et al. [9] used Life Cycle Analysis (LCA) to compare three different levels of recycling scenarios with respect to potential environmental impacts and resource recovery issues. The study was developed, however, on one single vehicle considered as a representative model. In the present study, the compared scenarios were actually implemented on a real crushing and sorting industrial facility, using in each experimental campaign a large number of real end-of-life vehicles representative of the diversity of the vehicles used in France and Europe. 
Furthermore, the scenarios were compared with respect to technical and environmental, but also social and economic issues, yet using a reasonably low number of experimentally accessible criteria.

\section{Materials and Methods}

\subsection{Description of the Scenarios and Experimental Approach}

Three scenarios were implemented at a full industrial scale in 3 successive experimental campaigns conducted from October 2009 to February 2011 in the industrial ELV shredding/sorting site of Saint Apollinaire, France. For each campaign, the industrial site was dedicated exclusively to the treatment of a sample of 120 ELVs selected specifically for the study for their representativeness. These vehicles were selected so that the sample was as representative as possible of the average national characteristics according to the data collected by the European Association of Car Manufacturers. The average mass and age of the ELVs in the samples was $989 \pm 1 \mathrm{~kg}$ and 14 years, respectively. The scenarios differed from each other by the degree of dismantling of the ELVs before shredding, as illustrated in Figure 1 and detailed below. Before each campaign, the site was totally cleared of all material remaining from the regular operations of the site. The shredder was initially operated for about 10 min without feeding it in order to discard all residual materials remaining from previous operations. In addition, all the collection containers under the hoppers of the sorting workstation and overband were completely emptied.

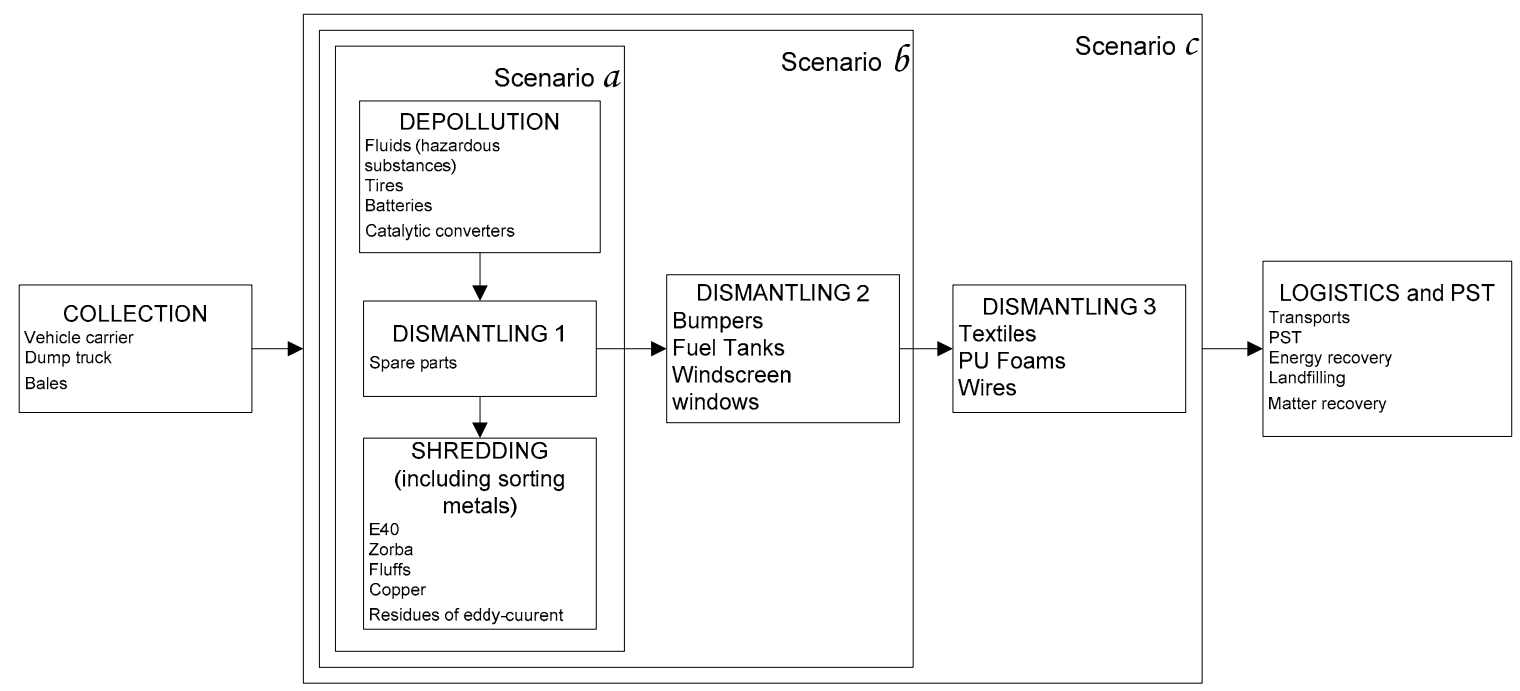

Figure 1. Overview of the 3 scenarios implemented experimentally at industrial scale. Multi-criteria analysis concerned the depollution, dismantling and shredding/sorting operations and did not include the end-of-life vehicles' (ELVs') collection phase or the post-shredding treatments (PST).

The scenarios were monitored by quantifying the mass flows of the different input and output materials, and analysing samples taken during the experimental assays. Dusts and gases emitted from the dismantling operations were analysed and the occupational time spent by the operators working on each phase of the dismantling stage was also recorded. The experimental protocols and the experimental data obtained were previously published by Schmid [5] and Schmid et al. [6,7]). The experimental results were used as inventory data in the present study.

\subsubsection{Low-Level Dismantling Scenario (a)}

The low-level dismantling scenario comprised regulatory depollution operations completed by the removal of a few valuable spare parts (all separable parts of the vehicle that can be reused in a vehicle of the same model or similar). This scenario is economically strongly driven by the market 
prices of steel and other metals. It is predominant when the business model is mostly or exclusively based on the recycling of ferrous and nonferrous metals.

\subsubsection{Medium-Level Dismantling Scenario (b)}

Scenario (b) included all operations of scenario (a), plus the disassembling of the following items:

- $\quad$ easily accessible and identifiable plastic materials, namely polypropylene (PP) bumpers, fenders and side trim strips, as well as High Density Polyethylene (HDPE) fuel tanks;

- $\quad$ all glass materials, namely: Laminated windscreens, side windows and rear windows of tempered white glass comprising metallic inclusions.

\subsubsection{High-Level Dismantling Scenario (c)}

Scenario (c) included all operations of medium-level scenario (b), plus the disassembling of:

- $\quad$ seats' textiles and polyurethane foams;

- electrical wiring accessible from the engine compartment that no further disassembly operation required.

\subsection{Shredding and Sorting Operations}

These operations were the same in all 3 scenarios. The shredder used was a $1250 \mathrm{HP}$ industrial shredder of about $30 \mathrm{t} / \mathrm{h}$ treatment capacity. The equipment included a feed belt, spider rotor, dust separation unit and a non-ferrous metal treatment unit by eddy current induction. The shredding and sorting operations generated five major output materials which were quantified and sampled specifically for analyses during the three campaigns:

- Shredded scrap metal (E40);

- Iron-copper components (coils, motors, electric wiring) extracted from the E40 output through manual sorting;

- Non-ferrous metals recovered during the sorting by eddy current induction were collected in two fractions of distinct particle size distributions (1-15 $\mathrm{mm}$ and 15-100 $\mathrm{mm}$ respectively);

- The non-metallic fraction, which was not recovered by eddy current sorting operations;

- Fluffs, corresponding to the low density shredder residues.

Other categories of materials produced in smaller quantities were also quantified and analysed.

2.3. Analytical Methods for Volatile Organice Compounds (VOCs), Polychlorinated dibenzo(p)dioxin and furan $(P C D D / F)$ and Polychlorinated Biphenyl (PCB)

VOCs were analyzed according to French standard NF 13526 [10] in gas samples taken from stack emissions. PCDDB-F were firstly concentrated from the liquid and solid samples by solvent extraction, using an ASE system, then analyzed by high-resolution gas chromatography coupled with mass spectrometry in accordance with the standards EN 1948 parts 1 to 3 for PCDD/F and EN 1948-4 for the PCB (EN 1948 [11]).

\subsection{Multi-Criteria Analysis}

\subsubsection{Boundaries of the System}

Multi-criteria analysis was applied to the operations described above which were actually monitored in the experimental campaigns. These operations included:

- Scenario (a): Complete depollution according to European regulations. The phase included the following operations: Removal of all fluids, i.e., residual fuel or gasoline, gear box and motor 
oils, cooling liquid and brake fluid, windshield-washer liquid, and antifreeze fluid. Removal of potentially hazardous parts, i.e., batteries, oil filters and catalytic converters were removed. The airbags were disabled and any possible LPG (Liquid Petroleum Gas) reservoirs removed. Finally, tyres were also removed;

- Scenario (b): Same operations as in (a), plus removal of all glass screen and windows, and some of the plastics;

- Scenario (c): Same operations as in (b), plus removal of foam from the seats, textile material and part of the electric wiring.

The operations relative to the collection of the ELVs and transportation to the shredding site, and the post-shredding treatments possibly done outside the shredding site were not included within the system boundaries.

\subsubsection{Selection of a System of Evaluation}

The system of evaluation was defined based on the general expectations classically expressed by stakeholders with regards to the implementation of sustainable development principles in industrial activities. The 3 scenarios were thus compared with respect to technical, environmental, social and economic issues using the experimental data collected in the corresponding 3 experimental campaigns. In order to make the approach feasible and possibly extendable to other sites and scenarios, it was decided to use a limited number of relatively easily accessible criteria.

Nine (9) criteria and 4 issues were selected as shown in Table 1. The criteria were defined to appreciate the positive or negative effects of the scenarios on different hazards relative to the 4 considered issues. For example, global warming was taken as a criterion of appreciation of "climate change" hazard within the environmental issue. The criteria themselves were assessed by using appropriate indicators which were quantified by well-established methods. Relatively specific indicators were preferred to general or synthetic ones as recommended by Coté [12]).

Table 1. System of evaluation used to compare the 3 scenarios.

\begin{tabular}{|c|c|c|c|c|}
\hline Issues & Criteria & & Indicators & Methods of Determination and Units \\
\hline \multirow{4}{*}{ Environmental } & Global warming & E1 & Greenhouse gases emission & $\begin{array}{l}\text { ADEME carbon balance method: Bilan } \\
\text { Carbone }{ }^{\circledR} \mathrm{V} 7\left(\mathrm{~kg} \cdot \mathrm{eq} \cdot \mathrm{CO}_{2}\right)^{\circ}\end{array}$ \\
\hline & Local impacts & E2 & Number of significant impacts & FMEA method: (Number of SEA ${ }^{\circ}$ ) \\
\hline & $\begin{array}{c}\text { Tropospheric } \\
\text { ozone production }\end{array}$ & E3 & VOC concentration in gases from shredder & GC-FID analysis $\left(\mathrm{mg} / \mathrm{Nm}^{3}\right)$ \\
\hline & Ecotoxicity & $\mathrm{E} 4$ & PCDD/F-PCB concentration in gases from shredder & GC-MS analysis $\left(\mathrm{Ng}\right.$ I-TEQ $/ \mathrm{Nm}^{3}$ ) \\
\hline Economic & Investment costs & F2 & Costs required for development & Spending budget $(€ /$ ELV) \\
\hline \multirow{2}{*}{ Social } & Occupational risks & S1 & Number of significant risks & FMEA Method (number of SR) \\
\hline & Employability & S2 & Number of jobs created & Worker time per ELV \\
\hline Technical & Performance & $\mathrm{T}$ & Global recovery rate & Recovered masses/ELVs masses (\%) \\
\hline
\end{tabular}

${ }^{\circ}$ Bilan Carbone is the standardized method proposed by ADEME (French Agency for Environment and Energy) to estimate greenhouse gases emissions from all stages of a given activity; ${ }^{\circ} \mathrm{FMEA}=$ "Failure Mode and Effects Analysis"; (risk assessment method) SEA = "Significant Environmental Aspects"; ${ }^{\circ \circ}$ ELV = "end of life vehicle(s)".

\subsubsection{Description of Evaluation Criteria}

The best scenario with regards to the defined system of evaluation was considered as the one that minimized criteria E1 to E4, F1, F2 and S1 while maximizing criteria S2 and T.

Environmental Issue

- Criterion E1: Global Warming 
E1 was evaluated by estimating greenhouse gas (GHG) emissions using the French method "Bilan Carbone" developed by ADEME. Direct and indirect emissions were evaluated using the emission factors $(\mathrm{EF})$ proposed in the method for the different types of industrial activities considered

- Criterion E2: Local Impacts

An (environmental) impact is called "local" when it is observed on a relatively small geographical scale. This category includes odorous emissions that usually do not exceed $500 \mathrm{~m}$, or soil contamination due to leak, for example. The term "significant" here refers to the level of appreciation given to the considered impact relative to the others.

E2 represented any potential significant impact of the considered operations on the natural media or ecosystems close to the industrial plant. The FMEA method was the tool used to assess the number of significant impacts.

- Criterion E3: Production of tropospheric ozone

The considered indicator was Volatile Organic Compound (VOC) emissions. It was evaluated by measuring VOC concentration in the channeled gaseous flows from the shredder. Analyses were done.

- Criterion E4: Ecotoxicity

Analyses done on the different flows of materials at the outlet of ELV shredders revealed in some studies by other authors the presence of traces of Polychlorinated dibenzo(p)dioxin and furan (PCDD/F) (PCDD/PCDF) (Borjeson et al. [13] and PCBs (Urano et al. [14]; Sakai et al. [15,16]). These pollutants may originate from the inputs themselves (oils, capacitors) or be formed through "de novo" synthesis during grinding operations (Trouve and Delfosse [17]). The indicator used was the emission of PCDD/PCDF/PCB-like chemicals.

Economic Issue

- Criterion F1: Operating Costs

The indicator used was an analytical assessment of the profitability of the different working positions of the treatment line by integrating accounting rules such as wage share calculations, depreciation or borrowing. The evaluation of economic performance was limited to the following items: mass of residues to be disposed of, payroll, and revenues from recovery of deconstruction materials (Schmid et al. [6,7]).

\section{- Criterion F2: Investments}

The indicator used was the additional expenditure required per treated ELV for the acquisition of the tools and equipment (such as bale presses, crushers, containers, etc.) and the necessary changes in operational procedures related to the implementation of the considered scenario. A 7-year depreciation period of the equipment was considered.

Social Issue

- Criterion S1: Occupational hazards

Previous studies reported that manual operations of ELV dismantling may significantly increase the risk factor for musculoskeletal disorders (Jonsson et al. [18]; Neumann et al. [19]). However, some types of configurations may be favorable (Kazmierczak et al. [20]). In addition to dismantling operations for which the operators were exposed to musculoskeletal disorders and exposure to noise, all operations at the interface of deconstruction and shredding and shredding itself were considered here. The indicator used was a composite indicator corresponding to the number of significant occupational risks determined using FMEA methodology in which a veto threshold was integrated above a certain level of hazard to human health (Roy [21]). 
- Criterion S2: Employability

This criterion expressed the number of jobs necessary to operate the different degrees of deconstruction in the scenarios. These jobs did not require specific qualification. The indicator was determined by monitoring the working time spent daily on the different operations of dismantling with respect to the number of ELVs treated in the considered period of time.

Technical Issue

\section{- Criterion T: Performance}

The performance criterion was the ability of the considered scenario to achieve the targets of performance of the European Directive 2000/53/CE [2]. Given the boundaries of the study, this criterion was not strictly representative of the actual performance of the overall treatment line, since it did not include post-shredding operations. However, it allowed for comparing the scenarios on the same basis. The indicator used was the overall recovery rate, which was determined by the mass ratio of the fractions of ELVs recovered in the form of material or energy over the total mass of ELVs in the representative sample of 120 ELVs treated in the scenario. It was assumed here that a technology and a market would be available to allow the actual reuse, recycling or energy recovery.

The ponderation of each criterion was done on the basis of stakeholder expectations collected from a panel of different categories of individuals including scientific experts, industrial managers, and regular citizens as shown in Table 2 The individuals constituting the panel were asked to express their propositions. A ponderation factor was initially proposed for each issue to the different categories of individuals, and the different members of the panel were asked to propose a ponderation for each criterion $(\mathrm{C})$. Table 2 shows the average values of the factors proposed by each category.

Table 2. Average ponderation of the issues and criteria (in \%) proposed by the different categories of experts and stakeholders (R) starting from an initial proposition (I).

\begin{tabular}{|c|c|c|c|c|c|c|c|c|c|c|c|c|c|}
\hline \multirow{2}{*}{$\begin{array}{c}\text { Criteria } \\
(j)\end{array}$} & \multirow{2}{*}{ Issues } & \multicolumn{2}{|c|}{$\begin{array}{l}\text { Industrial } \\
\text { Managers }\end{array}$} & \multicolumn{2}{|c|}{ Citizens } & \multicolumn{2}{|c|}{ Employees } & \multicolumn{2}{|c|}{ Mayors } & \multicolumn{2}{|c|}{$\begin{array}{c}\text { Public } \\
\text { Authorities }\end{array}$} & \multicolumn{2}{|c|}{ Scientists } \\
\hline & & I & $\mathbf{R}$ & I & $\mathbf{R}$ & I & $\mathbf{R}$ & I & $\mathbf{R}$ & I & $\mathbf{R}$ & I & $\mathbf{R}$ \\
\hline E1 & \multirow{4}{*}{ Environmental } & \multirow{4}{*}{30} & 20 & \multirow{4}{*}{30} & 30 & \multirow{4}{*}{50} & 20 & \multirow{4}{*}{40} & 20 & \multirow{4}{*}{40} & 40 & \multirow{4}{*}{40} & 20 \\
\hline E2 & & & 40 & & 20 & & 60 & & 20 & & 10 & & 40 \\
\hline E3 & & & 20 & & 25 & & 10 & & 30 & & 25 & & 20 \\
\hline $\mathrm{E} 4$ & & & 20 & & 25 & & 10 & & 30 & & 25 & & 20 \\
\hline $\mathrm{F} 1$ & \multirow{2}{*}{ Economic } & \multirow{2}{*}{30} & 80 & \multirow{2}{*}{20} & 60 & \multirow{2}{*}{20} & 60 & \multirow[b]{2}{*}{25} & 50 & \multirow{2}{*}{30} & 65 & \multirow{2}{*}{30} & 70 \\
\hline $\mathrm{F} 2$ & & & 20 & & 40 & & 40 & & 50 & & 35 & & 30 \\
\hline S1 & \multirow{2}{*}{ Societal } & \multirow{2}{*}{20} & 60 & \multirow{2}{*}{35} & 50 & \multirow{2}{*}{20} & 40 & \multirow{2}{*}{20} & 50 & \multirow{2}{*}{20} & 40 & \multirow{2}{*}{20} & 40 \\
\hline $\mathrm{S} 2$ & & & 40 & & 50 & & 60 & & 50 & & 60 & & 60 \\
\hline $\mathrm{T}$ & Technical & 20 & 100 & 15 & 100 & 10 & 100 & 15 & 100 & 10 & 100 & 10 & 100 \\
\hline
\end{tabular}

Finally, the average factors proposed by the whole panel of individuals was calculated as:

$$
\overline{p_{j}}=\left[\frac{1}{n} \sum_{i=1}^{n}\left(I_{i} \times R_{i}\right)\right] \times \frac{100}{\sum p_{j}}
$$

and the results given in Table 3.

Table 3. Factors of ponderation finally considered for each criterion in the study.

\begin{tabular}{cccccccccc}
\hline Criterion $(\boldsymbol{j})$ & E1 & E2 & E3 & E4 & F1 & F2 & S1 & S2 & T \\
\hline Ponderation $\left(\boldsymbol{p}_{\boldsymbol{j}}\right)$ & 9.8 & 13.0 & 8.3 & 8.3 & 13.7 & 10.0 & 10.9 & 12.3 & 13.7 \\
\hline
\end{tabular}




\subsubsection{Multi-Criteria Analysis Method}

Multi-criteria analysis is widely used as an aid to decision-making in the field of environmental management to compare alternative options and possibly select the best one based on a given value system. The approach is helpful in the process of comparison of the options with respect to a given set of criteria, but is not intended to "dictate" a decision. Several authors have contributed to develop Multi-Criteria Decision Analysis (MCDA) methods as an aid in the process of decision-making. For example, Cinelli et al. [22] have investigated the appropriateness of different MCDA methods to support life cycle sustainability assessment. Kiker et al. [23], Seager and Linkov [24], have studied the application of MCDA in environmental decision making, and more particularly its combination with Life Cycle Assessment.

The method used in the present study was PROMETHEE (Preference Ranking Organization Method for the Enrichment of feedback). It was developed in 1982 (Brans et al. [25]; Brans and Vincke [26]) and later supplemented by the graphical tool GAIA (Graphical Analysis for Interactive Aid) that allows a visual analysis of the results of all the parameters. For each criterion $j$, a ponderation factor $w_{j}$ (see Tables 2 and 3) and a function of preference $P_{j}$ were defined as $P_{j}(a, b)=G_{j}\left[f_{j}(a)-f_{j}(b)\right]$ with $0 \leq P_{j}(a, b) \leq 1$, where $a$ and $b$ corresponded to 2 options to be compared. $P_{j}$ was defined as a parametric or non-parametric function $G_{j}$ linked with preference threshold and $f_{j}(a)-f_{j}(b)$ the difference between the valuation $f_{j}(a)$ and $f_{j}(b)$ with respect to one given criterion in the form of a degree of preference ranking between 0 and 1 following different patterns as illustrated in Figure 2.

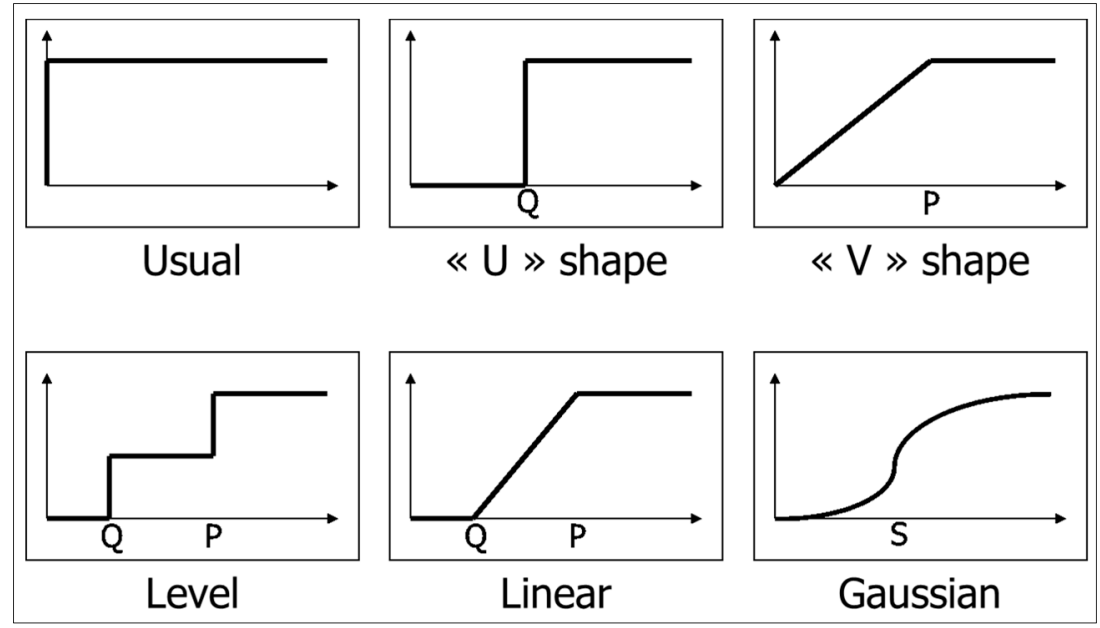

Figure 2. Types of preference functions considered in PROMETHEE method, and used to define pseudo criteria and preference structure.

The overall degree of preference of an action $a$ vs. an action $b$ with regard to all criteria was finally expressed by:

$$
\pi(a, b)=\sum_{j=1}^{k} w j \operatorname{Pj}(a, b)
$$

With the outranking graph obtained according to the preference relations existing between $a$ and $b$ actions, an outflow $\varphi^{+}$and an inflow $\varphi^{-}$were associated to each alternative action corresponding to their comparative strength and weakness:

$$
\begin{aligned}
\varphi^{+}(a) & =\frac{1}{n-1} \sum_{b \in A} \pi(a, b) \\
\varphi^{-}(a) & =\frac{1}{n-1} \sum_{b \in A} \pi(b, a)
\end{aligned}
$$


PROMETHEE method allowed to define:

(i) A partial order (PROMETHEE I) with 2 rankings of the alternative actions that matches the intercept of outflows and inflows as follows, using the following outflow and outflow rules:

- $\quad$ Marked preference $a$ vs. $b(a P b)$ if:

$$
\begin{gathered}
\varphi^{+}(a)>\varphi^{+}(b) \text { and } \varphi^{-}(a)<\varphi^{-}(b) \\
\varphi^{+}(a)=\varphi^{+}(b) \text { and } \varphi^{-}(a)<\varphi^{-}(b) \varphi^{+}(a)>\varphi^{+}(b) \text { and } \varphi^{-}(a)=\varphi^{-}(b)
\end{gathered}
$$

- $\quad$ No preference $(a I b)$ if: $\varphi^{+}(a)=\varphi^{+}(b)$ and $\varphi^{-}(a)=\varphi^{-}(b)$

- Incomparability $(a R b)$ in all other cases.

The method therefore allowed to rank the considered options allowing incomparability.

(ii) A full order (PROMETHEE II) based on the net flow defined by $\varphi(a)=\varphi^{+}(a)-\varphi^{-}(a)$ with the following modalities:

- $\quad$ Marked preference $(a P b)$ if $\varphi(a)>\varphi(b)$

- $\quad$ No preference $(a I b)$ if $\varphi(a)=\varphi(b)$

\section{Results and Discussion}

\subsection{Determination of the Percentage of Material and Energy Recovery (Criterion T)}

Criterion T expressed the ability of the scenarios to allow compliance with the targets of EU directive 200/53/CE [2]. This percentage was calculated considering the operations within the boundaries described in Section 2.4.1 above. Calculations were made as described above by considering the mass of ELVs used in each campaign (input) and the masses of the output fractions obtained from the shredding/sorting phase in each experimental campaigns, namely: Shredded scrap metal (E40), iron-copper components (coils, motors, electric wiring, non-ferrous metals and non-metallic fraction from eddy current induction), and the low density shredder residues (fluffs). It was assumed here that a technology and a market would be available to allow the actual reuse, recycling or energy recovery of these fractions.

Results given in Table 4 showed that the percentage of material and energy recovery logically increased with the degree of dismantling of the vehicles $(82.1 \%, 85.5 \%$ and $86.5 \%$ for scenarios (a), (b) and (c), respectively).

Table 4. Matrix of assessment.

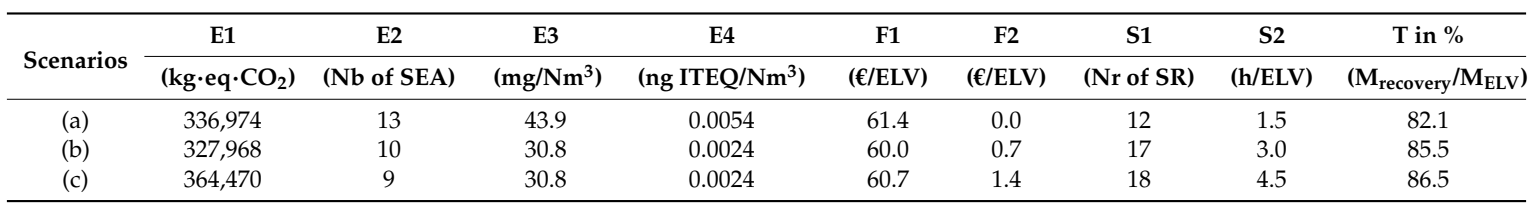

It was observed, however, that none of the scenarios achieved the target of EU directive (95\% reuse and recovery of which $10 \%$ maximum in energy) when implemented at the industrial scale under the technical conditions prevailing when the experimental campaigns were conducted (October 2009 to February 2011). Belboom et al. [27] obtained better technical performance in a study where they compared three dismantling scenarios of hybrid vehicles by conducing a life cycle assessment on industrial data collected in 2014 from a specialized company in Belgium. They concluded that the current "business as usual" scenario was in accordance with the requirement of the European Directive, 
with as high as $91.1 \%$ reuse and recycling and 5.8\% energy recovery. This high performance may be attributed to some specific characteristics of hybrid vehicles as compared to the much higher diversity of vehicles considered in the present study. It may also be related to the rapid improvement of available sorting technologies over the few years separating the period of collection of the data used in the two studies (around 2010 and 2014 respectively), which may have allowed increasing percentages of material recycling (for example metals recovery from alloys was significantly improved, Ohno et al. [28], and energy recovery (for example from the fluffs).

\subsection{Evaluation and Ranking of the Three Scenarios}

Table 4 shows the matrix of evaluation of the three scenarios with respect to the nine criteria. The evaluation of a scenario $(i)$ with respect to a given criterion Ek was expressed as $f_{\mathrm{Ek}}(i)$. For example, the evaluation of scenario (b) with respect to ecotoxicity criterion E4 was: $f_{\mathrm{E} 4}(b)=0.0024 \mathrm{ng} / \mathrm{Nm}^{3}$.

Table 5 indicates the function of preference selected for each criterion and the corresponding thresholds. The values obtained for $P j$ with respect to the nine selected criteria are shown in Table 5 and illustrated in Figure 3. They were used to determine the inlet and outlet flows given in Table 6 . The rankings of the three scenarios thereby obtained with partial ranking by PROMETHEE I and complete ranking by PROMETHEE II are shown in Figure 4.

Table 5. Determination of the preference functions.

\begin{tabular}{ccccccccccc}
\hline \multicolumn{2}{c}{ Criteria } & E1 & E2 & E3 & E4 & F1 & F2 & S1 & S2 & T \\
\hline Preference Function & Linear & V-Shape & V-Shape & V-Shape & Linear & V-Shape & Linear & V-Shape & V-Shape \\
\hline \multirow{4}{*}{ Threshold } & type & absolute & absolute & absolute & Relative & absolute & absolute & absolute & absolute & absolute \\
& $\mathrm{Q}$ & 1 & $\mathrm{n} / \mathrm{d}$ & $\mathrm{n} / \mathrm{d}$ & $\mathrm{n} / \mathrm{d}$ & 1 & $\mathrm{n} / \mathrm{d}$ & 1 & $\mathrm{n} / \mathrm{d}$ & $\mathrm{n} / \mathrm{d}$ \\
& $\mathrm{P}$ & 2 & 2 & 2 & 2 & 2 & 2 & 2 & 2 & 2 \\
& $\mathrm{~S}$ & $\mathrm{n} / \mathrm{d}$ & $\mathrm{n} / \mathrm{d}$ & $\mathrm{n} / \mathrm{d}$ & $\mathrm{n} / \mathrm{d}$ & $\mathrm{n} / \mathrm{d}$ & $\mathrm{n} / \mathrm{d}$ & $\mathrm{n} / \mathrm{d}$ & $\mathrm{n} / \mathrm{d}$ & $\mathrm{n} / \mathrm{d}$ \\
\hline \multirow{3}{*}{$P_{j}$} & $a$ & 0.0000 & -1.0000 & -1.0000 & -0.0015 & -0.2000 & 0.5250 & 10000 & -0.8750 & -1.0000 \\
& $b$ & 1.0000 & 0.2500 & 0.5000 & 0.0008 & 0.2000 & 0.0000 & -0.5000 & 0.0000 & 0.2500 \\
& $c$ & -1.0000 & 0.7500 & 0.5000 & 0.0008 & 0.0000 & -0.5250 & -0.5000 & 0.8750 & 0.7500 \\
\hline
\end{tabular}

\section{$\begin{array}{lllllllll}E 1 & E 2 & E 3 & E 4 & F 1 & F 2 & S 1 & S 2 & T\end{array}$}

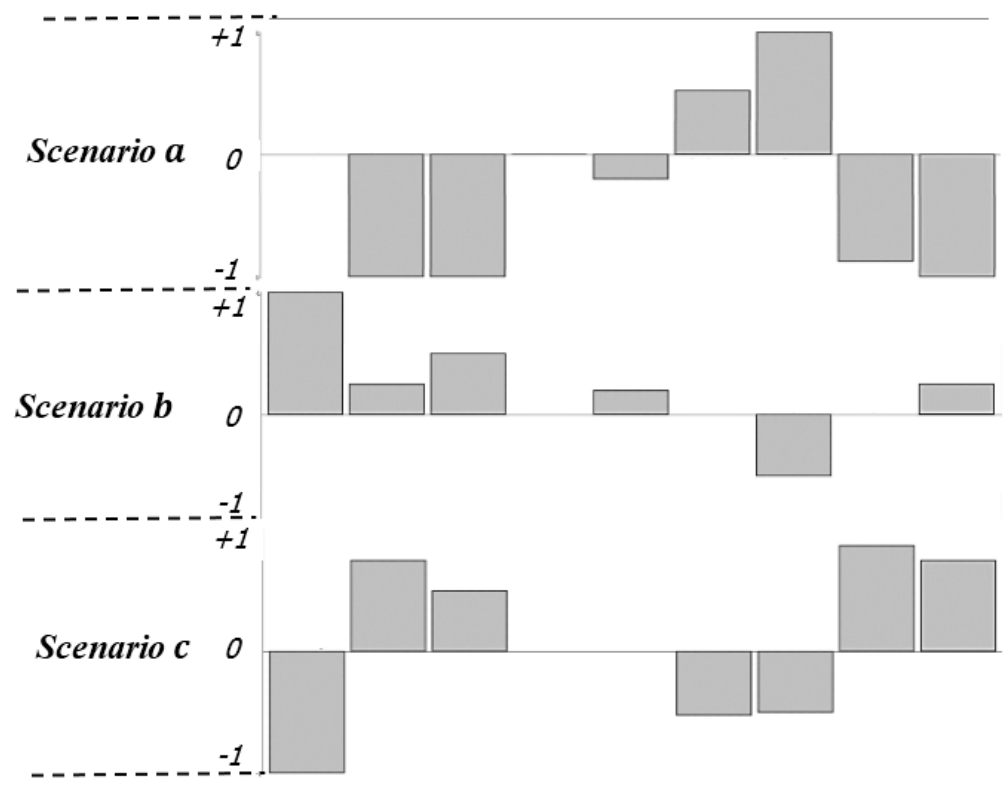

Figure 3. Preference profiles of the three scenarios with respect to the respective criteria. 
Table 6. Inflow, outflow and net flow of the 3 scenarios.

\begin{tabular}{cccc}
\hline Scenario & Inflow $\varphi^{-}$ & Outflow $\varphi^{+}$ & Net Flow $\boldsymbol{\varphi}$ \\
\hline (a) & 0.5341 & 0.2105 & -0.3236 \\
(b) & 0.1849 & 0.3641 & 0.1792 \\
(c) & 0.2050 & 0.3494 & 0.1444 \\
\hline
\end{tabular}

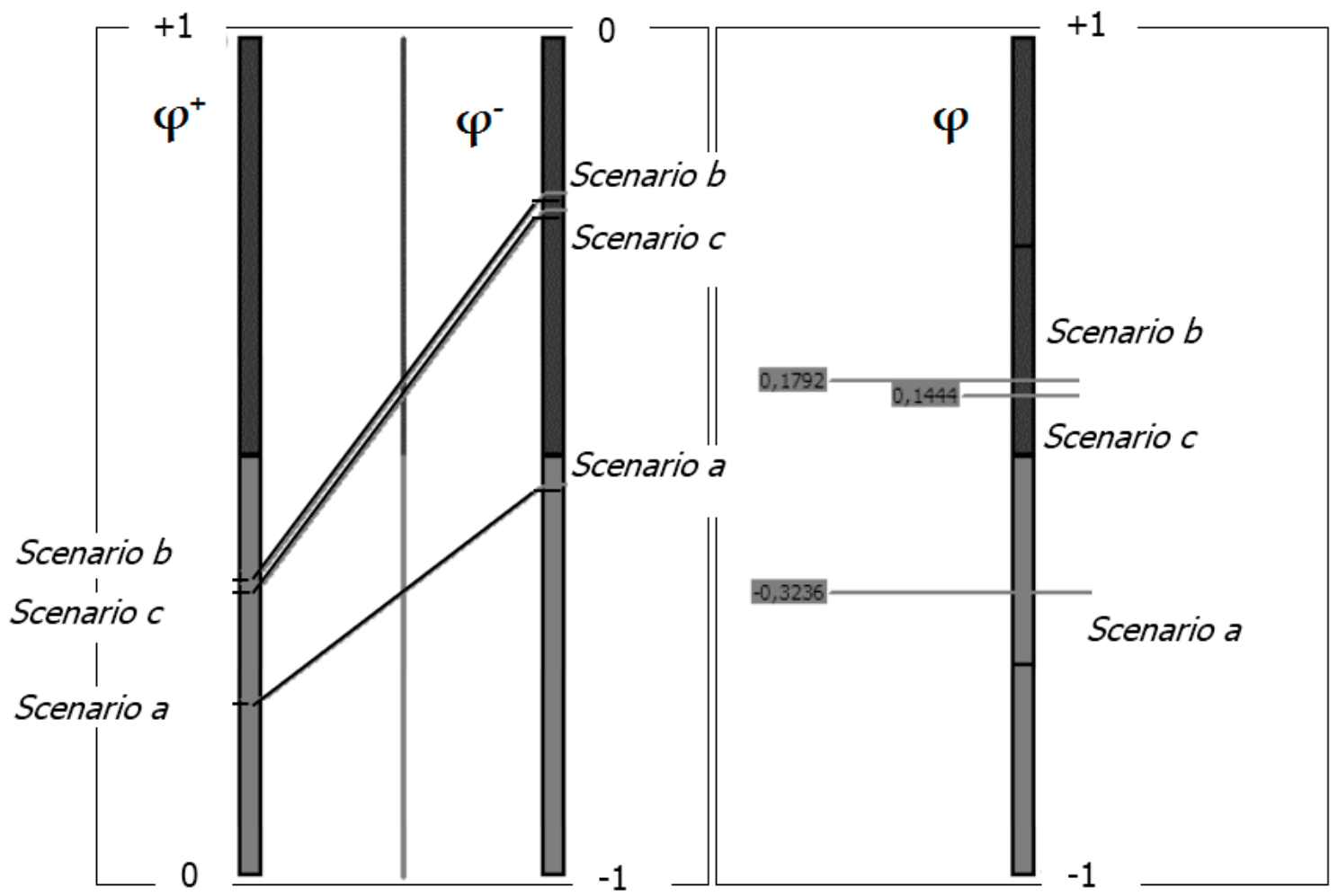

Figure 4. Partial (Left) and complete (Right) rankings of the three scenarios with PROMETHEE I and PROMETHEE II.

It can be seen in Figure 3 that the medium-level dismantling scenario (b) was systematically preferred to the other two alternative scenarios. The high-level dismantling scenario (c) was ranked second, and the low-level dismantling scenario (a) was ranked last.

Increasing the degree of dismantling from scenario (a) to scenario (c) required more numerous manual and mechanical operations, which in turn induced additional costs and potentially increased exposure of workers to occupational health hazards. Tian and Chen [29] studied the economics of manual dismantling of ELVs. They compared five dismantling scenarios to estimate the optimal dismantling level with respect to direct and indirect costs and sales and concluded that the scenario with the highest recycling rate was not the best one with respect to costs and profits. The present study reached the same conclusion with respect to a wider range of criteria including economics, environmental, social issues.

\subsection{Sensitivity Analysis}

Difficulties in decision-making processes regarding sustainable development issues arise from the possible conflicts between environmental, technological, social and economic factors. Furthermore, the decision-making process is made even more complex by the need to consider the possibly conflicting stakeholders' preferences.

The selection of ponderation factors for each criterion of evaluation is a methodological issue often debated in the application of MCDA. In the approach followed here, the process may be considered as 
relatively subjective, since it was based on the opinions of a panel of people. A sensitivity analysis was therefore conducted to estimate the influence of ponderation on the results of evaluation and the ranking. Reasonable modifications of the ponderation factors induced the changes shown in Figure 5.

E1 $(9.8 \%)[8 \%-39.2 \%]$

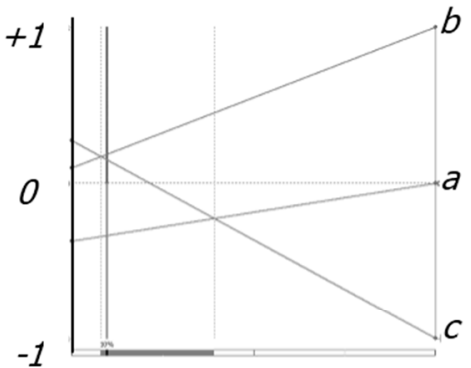

E4 (8.3\%) [0\%-100\%]

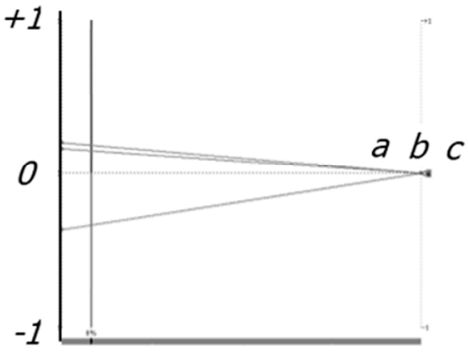

S1 $(10.9 \%)[0 \%-32.6 \%]$

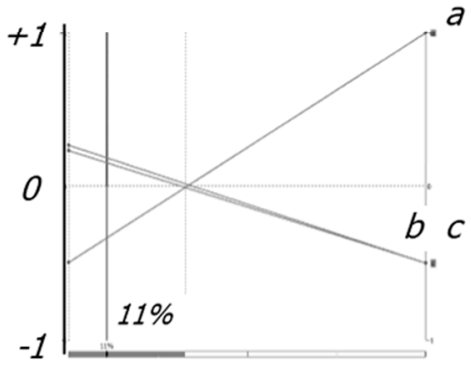

E2 $(13 \%)[0 \%-18.3 \%]$

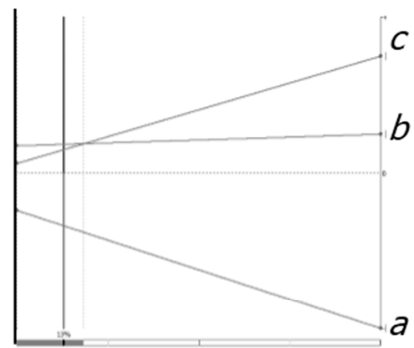

F1 $(13.7 \%)[0 \%-100 \%]$

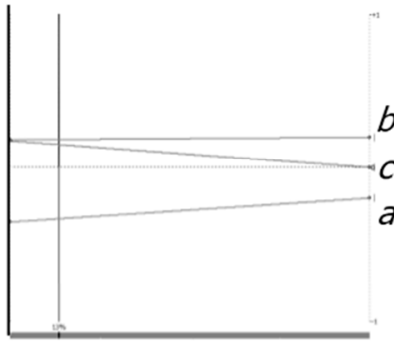

S2 $(12.3 \%)[0 \%-15.4 \%]$

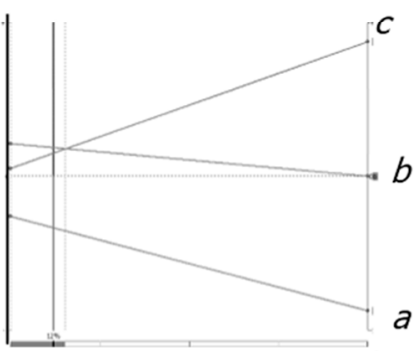

E3 $(8.3 \%)[0 \%-100 \%]$

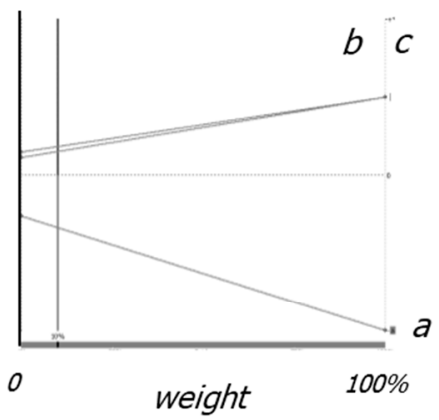

F2 (10\%) [3.6\%-38.4\%]

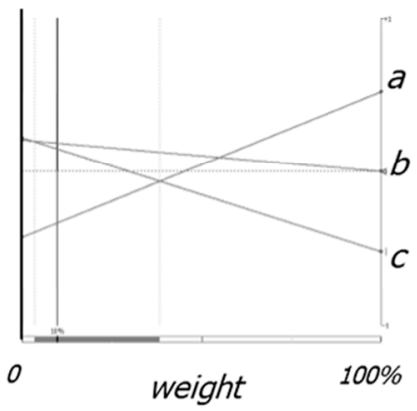

$\mathrm{T}(13.7 \%)[0 \%-19 \%]$

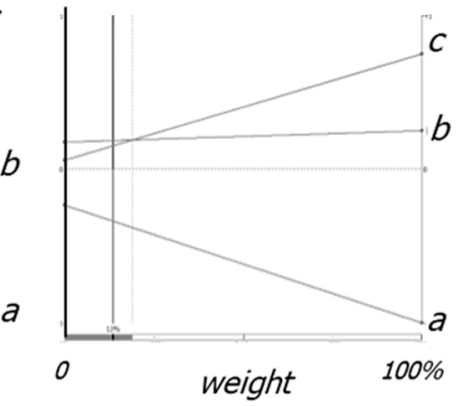

Figure 5. Effect of criteria ponderation on the ranking of the 3 alternative scenarios: (a) high-level dismantling; (b) medium-level dismantling and (c) low-level dismantling. Legend: CRITERION (actual ponderation used in \%) (lower limit-higher limit) of ponderation inducing no change in the final ranking of the scenarios.

The limits indicated in Figure 5 show the range of ponderation values of each individual criterion, which was found to induce no change in the final ranking of the scenarios. For example, the ponderation factor defined for criterion E1 was initially $9.8 \%$ and any modification down to $8 \%$ or up to $39.2 \%$ gave the same final ranking.

No effect on ranking was observed from the modifications of criteria E3 (tropospheric ozone production), E4 (ecotoxicity) and F1 (operational costs) in the whole range of variation studied (i.e., from $0 \%$ to $100 \%$ ). The ponderations of E1 (global warming) and S2 (employability) had stronger influences, however. Lowering the ponderations of E1 from $9.8 \%$ to $8 \%$, which was considered 
as a realistic possible variation, modified the ranking between scenarios (b) and (c) (medium- and high-level dismantling, respectively). Increasing S2 criteria by 3.1 from $12.3 \%$ to $15.4 \%$ had the same effect, but was not considered as realistic, based on the propositions of the panel of experts and stakeholders (Table 2).

However, the low-level dismantling scenario (a) was always ranked last, considering realistic ranges of variation (i.e., relative variations below $50 \%$ of initial ponderation level of each respective criterion). Scenario (a) would be ranked second instead of last only if factor E1 was to be multiplied by four (variation from its initial value of $9.8 \%$ up to $39.2 \%$ ). This very high variation was considered unrealistic.

\section{Conclusions}

This study reports a comparative multi-criteria evaluation with respect to technical and sustainability issues of dismantling and shredding operations of ELVs, according to the level of dismantling applied. Three scenarios with increasing dismantling levels were tested experimentally at the industrial scale on representative samples of 120 vehicles. Experimental data collected from three campaigns implemented and monitored at the industrial scale from October 2009 to February 2011 were used as feed data for multi-criteria analysis of the scenarios using PROMETHEE method. The scenarios allowed to achieve respectively $82.1 \%, 85.5 \%$ and $86.5 \%$ of material and energy recovery with respect to the operations included within the boundaries of the evaluated system. Integrating the post-shredding operations, which were not included in this evaluation, would increase the overall percentage of material and energy recovery but considering realistic levels of performance of these operations, none of the scenarios would allow achievement of the EC target of 95\%. The scenario with medium-level dismantling was ranked as the best scenario. This scenario included the stages of depollution, followed by the removal of easily accessible and identifiable plastics and glasses. The use of the PROMETHEE method appeared well adapted to the objective of the study. The method was easy to use and the results easily exploitable. A similar analysis was also done using Electre II (results not shown) and yielded to the same ranking. A sensitivity analysis showed that the modification within a reasonable range of the ponderation factors used for most criteria did not affect the ranking. Only criteria S2 (employability) and E1 (global warming) showed an effect on the ranking of the first two scenarios. The low-level deconstruction scenario (a) was always ranked as the worst scenario regardless of the ponderation in the range tested.

Acknowledgments: The experimental programme was co-funded by the French Agency for environment \& energy management ADEME. The authors wish to thank their partners for their support.

Author Contributions: A.S. organized and conducted the experimental campaigns, exploited the data, and wrote the first version of the article. P.N. supervised the experimental study. M.B.-H. provided recommendations regarding methodologies of multi-criteria analyses. R.G. supervised the PhD. Program, provided recommendations on how to exploit and present the results and contributed to that task, then wrote the intermediate and final versions of the article.

Conflicts of Interest: The authors declare no conflict of interest.

\section{References}

1. Lecointre, E.; Filmon, K. Observatoire de la filière Véhicules Hors D'usage-Année 2013; Technical Report of Contract: $\mathrm{N}^{\circ} 1002 \mathrm{C} 0123$ conducted by Antea Group on behalf of ADEME; Direction Economie Circulaire et Déchets; ADEME (Agence de l'Environnement et de la Maitrise de l'Energie): Angers, France, June 2015.

2. Directive 2000/53/EC of the European Parliament and of the Council of 18 September 2000 on end-of life vehicles; Directive 2000/53/EC; European Commission: Brussel, Belgium, 2000.

3. Fonseca, A.S.; Nunes, M.I.; Matos, M.A.; Gomes, A.P. Environmental impacts of end-of-life vehicles' management: Recovery versus elimination. Int. J. Life Cycle Assess. 2013, 18, 1374-1385. [CrossRef] 
4. Ahmed, S.; Ahmed, S.; Shumon, M.R.H.; Quader, E.F.M.A. A comparative decision-making model for sustainable end-of-life vehicle management alternative selection using AHP and extent analysis method on fuzzy AHP. Int. J. Sustain. Dev. World Ecol. 2015, 23, 83-97. [CrossRef]

5. Schmid, A. Valorisation des Véhicules Hors D'usage (VHU): Comparaison Multicritère de Scénarios de Démantèlement par une Étude Expérimentale Menée sur un Site Industriel de Déconstruction/Broyage. Ph.D. Thesis, Institut National des Sciences Appliquées (INSA) de Lyon, Villeurbanne, France, 2012; p. 210.

6. Schmid, A.; Naquin, P.; Gourdon, R. Etude expérimentale de l'incidence du niveau de démantèlement sur le taux de valorisation avant broyage des véhicules hors d'usage (VHU). Déchets Sci. Tech. 2012, 61, 30-48. [CrossRef]

7. Schmid, A.; Naquin, P.; Gourdon, R. Incidence of the level of deconstruction of end-of-life vehicles on the rate of material recovery: An industrial-scale experimental study. Resour. Conserv. Recycl. 2013, 72, 118-126. [CrossRef]

8. Mergias, K.; Moustakas, A.; Papadopoulos, M. Loizidou Multi-criteria decision aid approach for the selection of the best compromise management scheme for ELVs: The case of Cyprus. J. Hazard. Mater. 2007, 147, 706-717. [CrossRef] [PubMed]

9. Li, W.; Bai, H.; Yin, J.; Xu, H. Life cycle assessment of end-of-life vehicle recycling processes in China-Take corolla taxis for example. J. Clean. Prod. 2016, 117, 176-187. [CrossRef]

10. Émissions de sources fixes_Détermination de la concentration massique en carbone organique total à de fortes concentrations dans les effluents gazeux —Méthode du détecteur continu à ionisation de flame; NF 13526; AFNOR: Paris, France, May 2012.

11. Stationary source emissions-Determination of mass concentration of PCDDs/PCDFs and dioxin-like PCBs-Part 1: Sampling of PCDDs/PCDFs; Part 2: Extraction and clean-up of PCDDs/PCDFs; Part 3: Identification and quantification of PCDDs/PCDFs; Part 4: Sampling and analysis of dioxin-like PCBs; EN 1948; European Committee for Standardization: Brussels, Belgium, 2006.

12. Coté, S. Rechercher autre chose, mesurer autrement. In Les nouveaux utopistes du Développement Durable; Editions Autrement: Paris, France, 2003.

13. Börjeson, L.; Löfvenius, G.; Hjelt, M.; Johansson, S.; Marklund, S. Characterization of automotive shredder residues from two shredding facilities with different refining processes in Sweden. Waste Manag. Res. 2000, 18, 358-371. [CrossRef]

14. Urano, S.; Sakai, S.; Takatsuki, H. PCB in automobile shredder residue and its origin. In Proceedings of the 8th Symposium on Environmental Chemistry, Kyoto, Japan, 4 June 1996; pp. 50-51.

15. Sakai, S.; Urano, S.; Takatsuki, H. Leaching behavior of persistent organic pollutants (POPs) in shredder residues. Chemosphere 2006, 37, 2047-2054. [CrossRef]

16. Sakai, S.; Urano, S.; Takatsuki, H. Leaching behavior of PCB and PCDDs/DFs from some waste materials. Waste Manag. 2000, 20, 241-247. [CrossRef]

17. Trouve, G.; Delfosse, L. Etude Bibliographique sur les Conditions et Mécanismes de Formation à Basses Températures $\left(200\right.$ à $\left.400{ }^{\circ} \mathrm{C}\right)$ des Dibenzodioxines, Dibenzofurannes Polychlorés; Technical Report No. 96-0208/1A; RECORD: Lyon, France, 1997.

18. Jonsson, D.; Medbo, L.; Engström, T. Some considerations relating to the reintroduction of assembly lines in the Swedish automotive industry. Int. J. Oper. Prod. Manag. 2004, 24, 754-772. [CrossRef]

19. Neumann, W.P.; Winkel, J.; Medbo, L.; Magneberg, R.; Mathiassen, S.E. Production system design elements influencing productivity and ergonomics in a case study of parallel and serial flow strategies. Int. J. Oper. Prod. Manag. 2006, 26, 904-923. [CrossRef]

20. Kazmierczak, K.; Neumann, P.; Winkel, J. A case study of serial-flow car disassembly: Ergonomics, productivity and potential system performance. Hum. Factors Ergon. Manuf. 2007, 17, 331-351. [CrossRef]

21. Roy, A. Evaluation de la Performance Environnementale de Sites Industriels; Cahier LAMSADE 243; Université Paris Dauphine: Paris, France, 2006; p. 36.

22. Cinelli, M.; Coles, S.R.; Kirwan, K. Analysis of the potentials of multi criteria decision analysis methods to conduct sustainability assessment. Ecol. Indic. 2014, 46, 138-148. [CrossRef]

23. Kiker, G.A.; Bridges, T.D.; Varghese, A.; Seager, T.P.; Linkov, I. Application of multicriteria decision analysis in environmental decision making. Integr. Environ. Assess. Manag. 2005, 1, 95-108. [CrossRef] [PubMed]

24. Seager, T.P.; Linkov, I. Coupling multicriteria decision analysis and life cycle assessment for nanomaterials. J. Ind. Ecol. 2008, 12, 282-285. [CrossRef] 
25. Brans, J.P.; Mareshal, B.; Vincke, P. PROMETHEE, a new family of outranking methods in multicriteria analysis. In Operational Research 84; Brans, J.-P., Ed.; Elsevier Science Publishers B.V.: Amsterdam, The Netherlands, 1984; pp. 408-421.

26. Brans, J.P.; Vincke, P.H. A preference ranking organisation method: The PROMETHEE method for multiple criteria decision-making. Manag. Sci. 1985, 31, 647-656. [CrossRef]

27. Belboom, S.; Lewis, G.; Bareel, P.-F.; Léonard, A. Life cycle assessment of hybrid vehicles recycling: Comparison of three business lines of dismantling. Waste Manag. 2016, 50, 184-193. [CrossRef] [PubMed]

28. Ohno, H.; Matsubae, K.; Nakajima, K.; Kondo, Y.; Nakamura, S.; Nagasaka, T. Toward the efficient recycling of alloying elements from end of life vehicle steel scrap. Resour. Conserv. Recycl. 2015, 100, 11-20. [CrossRef]

29. Tian, J.; Chen, M. Assessing the economics of processing end-of-life vehicles through manual dismantling. Waste Manag. 2016, 56, 384-395. [CrossRef] [PubMed]

(C) 2016 by the authors; licensee MDPI, Basel, Switzerland. This article is an open access article distributed under the terms and conditions of the Creative Commons Attribution (CC-BY) license (http://creativecommons.org/licenses/by/4.0/). 